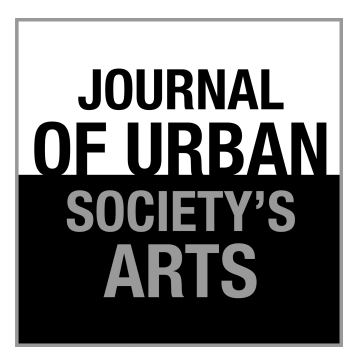

Volume 3 Nomor 1 , April 2016: 19-26

\section{Fashion Budaya Nasional dalam Konteks Wawasan Kebangsaan: Studi Kasus pada Jember Fashion Carnaval}

Agustinus Tampubolon dan Cecep Darmawan

Departemen Pendidikan Kewarganegaraan

Sekolah Pascasarjana Universitas Pendidikan Indonesia, Bandung

Tlp.081223768210, E-mail: a.tampubolon@gmail.com

\begin{abstract}
ABSTRAK
Penelitian ini bertujuan untuk menjelaskan konstruksi makna fashion yang berkaitan dengan konsep wawasan kebangsaan. Desain penelitian yang digunakan adalah kualitatif dengan metode fenomenologi. Data dikumpulkan melalui wawancara, observasi mendalam, dan studi dokumentasi. Hasil penelitian menunjukkan bahwa: (1) fashion sebagai penguat wawasan kebangsaan melalui Jember Fashion Carnaval (JFC) berkaitan dengan aspek kreativitas, tema, dan simbol-simbol; (2) pesan fashion berkaitan dengan wawasan kebangsaan karena memuat nilai-nilai persatuan dan kesatuan yang dilandasi semangat dan usaha rela berkorban. Pesan yang menggambarkan konstruksi nilai kebangsaan yang dimiliki secara bersama-sama dapat dijadikan sebagai pedoman hidup antarmasyarakat berbangsa dan bernegara; (3) proses mengonstruksi nilai-nilai kebangsaan melalui fashion ditunjukkan dengan partisipasi atau keterlibatan secara aktif dan bertanggung jawab dalam mengikuti program pelatihan dan pembimbingan In House Training selama lima bulan menjelang pelaksanaan JFC. Program ini meliputi pemilihan tema berdasarkan riset dan pengkajian sampai pada acara puncak, yaitu grand carnival.
\end{abstract}

Kata kunci: fashion, budaya nasional, wawasan kebangsaan, JFC

\begin{abstract}
The Fashion of National Culture in the Context of National Insight: CaseStudy on Jember Fashion Carnaval. This study aims to explain the construction meaning offashion related to the concept of national insight. The study is qualitative with phenomenological method. Data collection technique was carried out by interviews, in-depth observation, and documentation studies. The results show that: (1) disclosed matters of the fashion as a reinforcement of the concept of national insight through Jember Fashion Carnaval (JFC) deal with aspects of creativity, themes, and symbols in carnival costume; (2) the fashion statement relates to the concept of national insight because it contains the values of unity and the spirit of understanding and self-sacrificing efforts. The messages describe how the construction of the national values held together can be used as guidelines for intra-national and state of life; (3) the process of constructing the national values through fashion is indicated by participation or involvement actively and responsibly in the training program and coaching. The program called In House Training for five months before the implementation of JFC includes the selection of themes based on the research and studies until the main event, which is a grand carnival.
\end{abstract}

Keywords: fashion, national culture, nationality insight, JFC

\section{Pendahuluan}

Wawasan kebangsaan tidak terlepas dari kebudayaan yang berakar dari nilai-nilai budaya nasional. Pembangunan eksistensi suatu bangsa akan terjaga melalui kebudayaan yang diciptakan oleh manusia itu sendiri. Berbagai simbol kebudayaan diwujudkan sebagai ungkapan manusia 
dalam menyampaikan makna identitas kepribadian dirinya yang berbeda dengan orang lain. Melalui simbol, manusia secara alamiah menunjukkan ide, gagasan, dan konsep pemikirannya yang kemudian diwujudkan dalam berbagai hal khususnya berupa nilai-nilai yang terlihat. Nilai-nilai itu dapat berupa sikap dan tingkah laku manusia sebagai wujud dari identitasnya. Oleh karena itu untuk membangun identitas dibutuhkan media efektif dan partisipatif yang mampu menangkap nilai-nilai moral masyarakat.

Media tersebut adalah ruang kreatif bagi masyarakat untuk menuangkan ide, konsep, dan pengetahuan yang selanjutnya dialami oleh dirinya dan berguna bagi kepentingan bersama. Adanya usaha dan upaya tersebut masyarakat dapat secara langsung berpartisipasi mengolah, membentuk, dan membangun jati dirinya sebagai warga negara yang baik dan cerdas. Hal ini akan membangun masyarakat yang tidak hanya mengetahui simbolsimbol kebudayaan, namun memahami secara jelas makna filosofis yang terkandung di balik simbol tersebut.

Jember Fashion Carnaval (JFC) dipilih sebagai media untuk membangun wawasan kebangsaan yang berakar pada budaya nasional. Berbagai prestasi dan keunggulan disampaikan JFC kepada masyarakat Indonesia. Walau demikian ada sebagian masyarakat yang menganggap bahwa JFC hanya pagelaran yang sekadarnya saja. Masyarakat cenderung melihat fenomena fashion dalam JFC hanya dari permukaan saja dan tidak memahami makna yang disampaikan di balik gejala yang tampak. Bahkan ada yang menganggap bahwa kegiatan ini pada awalnya tidak sesuai dengan budaya lokal Indonesia.

Perlu dipahami bahwa terbentuknya suatu bangsa juga dipengaruhi oleh rasa kebangsaan untuk mencapai kemerdekaan yang dilandasi persatuan. Tauchid (2015) menjelaskan pemikiran Ki Hajar Dewantoro bahwa akibat dari letaknya bagianbagian negeri kita sebagai "kepulauan", maka penjajahan Belanda, dengan politiknya memecah belah, dapat memisah-misahkan rakyat, sekalipun hanya pada hidup lahirnya; rasa batin dan keinsafan rakyat akan adanya kesatuan hidup sebagai bangsa, tetap ada. Adanya kesamaan rasa dan jiwa dapat disebut dengan rasa kebangsaan. Rahmanto \& Yani (2015) juga mengungkapkan bahwa wawasan kebangsaan menegaskan bahwa kesejahteraan rakyat lebih dari hanya kemakmuran yang paling tinggi dari sejumlah orang yang paling hebat. Dalam kaitan ini Nuryanti (2014) menambahkan bahwa wawasan kebangsaan merupakan hasil perkembangan dari dinamisasi rasa kebangsaan dalam mencapai cita-cita bangsa. Pemikiran ini dapat dijelaskan bahwa wawasan kebangsaan adalah wawasan mengenai rasa memiliki bangsa, semangat berbangsa, dan dilandaskan pada kebersamaan yang satu dan utuh. Wawasan kebangsaan mewujudkan rasa dan semangat kebangsaan yang sarat akan nilai-nilai persatuan dan kesatuan yang menjadi sumber kekuatan dan keutuhan bangsa.

Hendrariningrum \& Susilo (2008) menjelaskan bahwa fashion berasal dari bahasa Latin, factio, yang artinya membuat atau melakukan. Arti kata asli fashion, oleh karena itu mengacu pada kegiatan; fashion merupakan sesuatu yang dilakukan seseorang, tidak seperti dewasa ini, yang memaknai fashion sebagai sesuatu yang dikenakan seseorang. Arti asli fashion mengacu pada ide tentang fetish atau objek fetish. Fashion diartikan sebagai pembangunan jati diri atau identitas oleh seseorang. Simmel (2006) bahkan mengemukakan hasil tulisannya dalam The American Journal bahwa fashion is a form of imitation and so of social equalization, but, paradoxiacally in changing incessantly, it differentiates one time from another and one social stratum form another.

Bernard melalui karyanya Fashion as Communication (Berek, 2014) juga menjelaskan bahwa "fashion merupakan fenomena kultural, dalam artian fashion merupakan cara yang digunakan suatu kelompok atau individu untuk mengonstruksi dan mengomunikasikan identitasnya dan orang cenderung membuat penilaian berdasarkan atas apa yang dipakai oleh orang lain".

Arvanitidou (2011) menjelaskan bahwa fashion merupakan produk budaya yang bertujuan menyampaikan suatu pesan kepada orang lain. Fashion memiliki simbol identitas sosial yang menyimpan suatu persepsi berbeda bagi orang yang melihat. Melalui fashion, seseorang dapat 
menginterpretasikan karakteristik budaya berdasarkan apa yang berlaku dengan bermakna ganda (ambigu).

Membangun karakter warga negara merupakan hal yang sangat penting untuk menjaga eksistensi suatu bangsa atau negara. Eksistensi suatu bangsa bisa tetap bertahan apabila bangsa tersebut memiliki identitas yang kuat (Himawan 2014).

Habermas (Hardiman, 2009) memandang bahwa tindakan sosial adalah unsur dasar pembentuk masyarakat. Hal ini dapat dipahami bahwa masyarakat sebagai tenunan yang rumit dari tindakan-tindakan sosial tersebut. Tindakan sosial berkaitan erat dengan orang lain. Tindakan tersebut dapat memengaruhi orang lain untuk bertindak sesuai dengan apa yang dilakukan oleh individu tersebut. Hidayat \& Widjanarko (2008) menjelaskan bahwa dalam mencanangkan agenda perubahan perilaku, teori tindakan manusia (buman action) diperlukan sebagai acuan. Dalam kajian sosiologis tiap tindakan seseorang tidaklah terjadi dalam "ruang hampa", tetapi terkait erat dengan orang lain (oriented the other) atau terjadi dalam "situasi sosial" tertentu. Konsep ini menjelaskan bahwa tindakan sosial menimbulkan interaksi sosial bagi struktur sosialnya sehingga dapat memberikan perubahan bagi dirinya atau orang lain.

Berger dan Luckmann (Zen, 2004) mengungkapkan bahwa pengertian dan pemahaman terhadap sesuatu muncul akibat komunikasi dengan orang lain. Syam (2005) menjelaskan bahwa berdasarkan teori konstruksi sosial, manusia menjadi agen di dalam konstruksi aktif dari realitas sosial, dimana ketika mereka melakukan tindakan bergantung pada pemahaman atau pemberian makna pada tindakan mereka. Henslin \& James (2006) mengungkapkan bahwa ide kita membantu penentuan realitas.

Pada dasarnya, tujuan Pendidikan Kewarganegaraan $(\mathrm{PKn})$ adalah menanamkan nilainilai kebangsaan dan rasa cinta tanah air. Dalam pengertian yang normatif tercantum pada Pasal 37 Undang-Undang Nomor 20 Tahun 2003 bahwa Pendidikan Kewarganegaraan dimaksudkan untuk membentuk peserta didik menjadi manusia yang memiliki rasa kebangsaan dan cinta tanah air. Wahab \& Sapriya (2011) mencoba menjelaskan pendapat Sumantri untuk membantu para praktisi merinci tujuan PKn yang meliputi: (1) Ilmu pengetahuan, yang mencakup fakta, konsep, dan generalisasi; (2) keterampilan intelektual, dari keterampilan sederhana sampai keterampilan kompleks, dari penyelidikan sampai kesimpulan yang sahih, dari berpikir kritis sampai berpikir kreatif; (3) sikap, meliputi nilai, kepekaan, dan perasaan; dan (4) keterampilan sosial.

Budimansyah \& Suryadi (2008) menjelaskan konfigurasi atau kerangka sistemik PKn dibangun atas dasar paradigma sebagai berikut: Pertama, PKn secara kurikuler dirancang sebagai subjek pembelajaran yang bertujuan mengembangkan potensi individu agar menjadi warga negara Indonesia yang berakhlak mulia, cerdas, partisipatif, dan bertanggung jawab. Kedua, Pkn secara teoretik dirancang sebagai subjek pembelajaran yang memuat dimensi-dimensi kognitif, afektif, dan psikomotor yang bersifat konfluen atau saling berpenetrasi dan terintegrasi dalam konteks substansi ide, nilai, konsep, dan moral Pancasila, kewarganegaraan demokratis, dan bela negara. Ketiga, PKn secara programatik dirancang sebagai subjek pembelajaran yang menekankan pada isi yang mengusung nilai-nilai dan pengalaman belajar. Dalam pengertian yang lain, Hermawan menjelaskan bahwa pembelajaran pembentukan karakter bangsa melalui mata pelajaran PKn atau Civic Education perlu diarahkan agar peserta didik dapat mengembangkan kecerdasan warga negara (civic intelligence) dalam dimensi spiritual, rasional, emosional, dan sosial; tanggung jawab warga negara (civic responsibility); serta partisipasi warga negara (civic participation).

\section{Pembahasan}

Hasil temuan penelitian menunjukkan bahwa hakikat fashion dalam wawasan kebangsaan berkaitan dengan kreativitas yang dimiliki oleh setiap orang. Berkaitan dengan konsep tersebut, tujuan pendidikan kewarganegaraan adalah sebagai: (1) ilmu pengetahuan yang mencakup fakta, konsep, dan generalisasi; (2) keterampilan intelektual, dari keterampilan sederhana sampai keterampilan kompleks, dari penyelidikan sampai kesimpulan yang 
sahih, dari berpikir kritis sampai berpikir kreatif; (3) sikap, meliputi nilai, kepekaan, dan perasaan; dan (4) keterampilan sosial. JFC melalui fashion membangun wawasan kebangsaan yang dilandasi pada semangat untuk terus berkreativitas dan berkarya untuk mengenalkan baik Jember maupun Indonesia di internasional. Hal ini sesuai dengan apa yang dijelaskan oleh Kociatkiewicz \& Johansson (2011), bahwa Festivals and other cultural events are seen as a means to contribute to a positive image of a place and to create employment opportunities to further economic growth and entrepreneurial confidence. Eicher \& Higgins (1992) menjelaskan bahwa fashion berbicara mengenai seluruh hasil dari kebudayaan manusia baik yang berwujud maupun tidak. Singkatnya, dalam kreativitas fashion ada nilai-nilai sosial yang dibangun.

Pandangan JFC terhadap tema yang dikonstruksikan oleh fashion juga memuat pesan budaya dengan menghadirkan konsep-konsep global yang mewakili warisan budaya bangsa dan dunia. Tema menggambarkan bagaimana manusia mengaktualisasikan kemampuannya sesuai dengan apa yang dimiliki sehingga menjadi aktivitas dari kebudayaan sekarang. Hal ini seturut dengan pendapat Suharson (2014) bahwa karya seni mengandung makna atau mengekspresikan sesuatu. Berkaitan dengan hal tersebut, perspektif global yang diciptakan oleh JFC melalui tema dalam pendidikan kewarganegaraan dipandang sebagai bentuk tanggung jawab dan kepedulian sebagai warga global. Sebagai warga negara global sudah semestinya untuk menyiapkan siswa sebagai warga negara muda secara formal dan informal untuk terlibat dan berpartisipasi dalam kehidupan masyarakat dunia (Wahab \& Sapriya 2011).

Perspektif JFC terhadap isu-isu global menunjukkan beberapa dimensi yang oleh Hanvey uraikan sebagai kesadaran perspektif yaitu kesadaran akan kondisi planet bumi, kesadaran antarbudaya, pengetahuan dinamika global, dan kesadaran pilihan manusia (Ferreira 2013). Lima dimensi perspektif global ini menjelaskan bahwa JFC memiliki kesadaran perspektif yang tidak hanya sekadar pengetahuan atau persepsi semata namun telah ditunjukkan pada sikap dan tindakan nyata untuk dikonstruksikan kepada orang lain.
Fashion, dress, and adornment are important badges of identity since they locate the actor either inside or outside a particular group. Therefore, social constructions of embodiment and bodily action are intrinsic components of cultural identities transformed by global forces (Langman 2003).

Kesadaran global melalui tema tanpa disadari telah memberi gambaran bahwa JFC memiliki sikap sebagai warga negara dunia. Tema dengan pesan global yang memuat kesadaran terhadap cara memandang dunia adalah hakikat dari pendidikan kewarganegaraan. Oleh karena itu dibutuhan pemahaman dan strategi untuk mengaitkan pendidikan formal dan informal bagi peserta didik agar tercipta wawasan kebangsaan (Huang \& Chen 2013).

Tindakan ini secara khusus termasuk dalam pendidikan kewarganegaraan yang bersifat multidimensional. Hal ini menjelaskan bahwa tindakan JFC untuk menanamkan rasa kebangsaan sesuai dengan tujuan PKn seperti yang diamanatkan secara normatif di bagian penjelasan Pasal 37 Undang-Undang Nomor 20 Tahun 2003 tentang Sistem Pendidikan Nasional dijelaskan bahwa Pendidikan Kewarganegaraan dimaksudkan untuk membentuk peserta didik menjadi manusia yang memiliki rasa kebangsaan dan cinta tanah air. Konsep tema yang memuat nilai-nilai kebangsaan menandakan bahwa keberadaan JFC di masyarakat termasuk dalam domain sosial kultural PKn karena berkaitan dengan konsep dan praksis PKn di lingkungan masyarakat. Cogan (Winataputra \& Budimansyah, 2012) juga menjelaskan bahwa secara konseptual "citizenship" memiliki lima atribut pokok, yakni: "... a sense of identity; the enjoyment of certains rights; the fulfilment of corresponding obligations; a degree of interest and involvement in public affairs; and acceptance of basic societal values". Seorang warga negara sebaiknya memiliki lima ciri utama tersebut, yaitu jati diri; kebebasan untuk menikmati hak tertentu; pemenuhan kewajibankewajiban terkait; tingkat minat dan keterlibatan dalam urusan publik; dan pemilikan nilai-nilai dasar kemasyarakatan.

Berdasar penelitian juga ditemukan bahwa wawasan kebangsaan yang dikonstruksikan oleh 
fashion mengungkapkan pengetahuan dan wawasan tentang Indonesia dan dunia melalui simbol-simbol fashion. Kuntjara (2006) mengungkapkan bahwa setiap masyarakat mempunyai dan menggunakan simbol-simbol tertentu yang dipakai sebagai tanda. Simbol-simbol tersebut bisa berupa sesuatu yang konkret seperti benda atau gambar, atau suatu ide yang abstrak. Makna sebuah simbol tidak bisa serta merta diketahui, tetapi dibutuhkan suatu penafsiran. Pendapat ini didukung oleh Putra \& Ahimsa (2014) yang menggambarkan kebudayaan sebagai keseluruhan tanda dan simbol yang diperoleh manusia dalam kehidupannya sebagai warga suatu masyarakat atau komunitas, dan digunakan untuk beradaptasi dengan lingkungan atau mempertahankan keberadaannya sebagai makhluk hidup.

Pada dasarnya perkembangan seni mutakhir atau seni kontemporer telah disebutkan tidak dapat dipisahkan dari sistem sosial, ekonomi, dan budaya sebuah masyarakat; tetapi juga secara khas mampu menunjukkan manifestasi estetik dan refleksi nilai yang bersifat kritis terhadap sistem ekonomi-sosial kultural yang menghidupinya (Himawan \& Nugroho 2014). Widhagdo (2010) menjelaskan baik individu maupun kolektivitas senantiasa memiliki identitas, yang dengan perantaraan lambang-lambangnya dapat dikenal serta dibedakan dari identitas lain dari jenisjenisnya. Harmoko (2009) mengungkapkan bahwa kemampuan manusia mengembangkan peralatanperalatan dan cara mengendalikannya (teknologi) itu dimungkinkan karena daya pikir berperlambang yang tidak dimiliki oleh makhluk lainnya. Hal ini juga dijelaskan oleh Sisworo bahwa fungsi dan peranan kesenian tradisi dalam masyarakat juga akan berubah dan berkembang mengikuti pola kehidupan masyarakatnya. Manusia meskipun yakin tentang siapa dirinya, tetapi perlu diketahui bahwa setiap orang tidak mampu menghadapi kesulitannya sendiri dan membutuhkan orang lain untuk menyampaikan apa yang dirasakannya (Jannah 2012). Hasil kebudayaan yang diciptakan fashion dalam JFC berupa simbol menggambarkan masyarakat hidup dalam karakter yang beragam dan berbeda serta saling berdampingan berdasarkan nilai-nilai sosial masyarakat Indonesia. Simbol- simbol fashion memuat wawasan kebangsaan yang saling melengkapi sehingga tidak hanya meninjau diri sendiri tetapi juga orang lain. Konsep kebudayaan mengimplikasi adanya hubungan dengan akumulasi simbol-simbol yang dimiliki bersama yang merupakan representasi dari dan memiliki arti penting di dalam masyarakat (Jenks 2013).

\section{Pesan Tema JFC dan Wawasan Kebangsaan}

Pesan yang disampaikan oleh JFC tentang wawasan kebangsaan adalah menciptakan kesadaran masyarakat Indonesia agar memiliki rasa kebanggaan, cinta, dan semangat kebangsaan terhadap bangsa dan negaranya. Aji \& Effendi (2014) bahkan menjelaskan peran JFC dalam membantu Semarang Night Carnival di Kota Semarang. Dalam tulisannya ia menuliskan Inviting Consultants and Coaches from Jember Fashion Carnival (JFC). JFC melalui pesan kebangsaan bertujuan membangun rasa kepedulian dan perhatian bagi daerahdaerah lainnya untuk bersama-sama maju dan hidup mandiri berdasarkan kekuatan lokal yang dimiliki. Secara khusus, JFC melihat tantangan sebagai kekuatan, dengan membuat karnaval yang memuat pesan-pesan moral yang menyadarkan masyarakat Jember tentang cita-cita pembangunan kota karnaval sebagai kota kreatif yang berkembang dan maju di bidang pariwisata (Jannah 2012).

Barata (2010) mengungkapkan bahwa suatu komunikasi yang berinteraksi sosial dapat tercipta bergantung dari pemaknaan yang ditimbulkan oleh si penerima terhadap si pemakai fashion. Pasal 1 angka 1 Peraturan Menteri Dalam Negeri No. 71 Tahun 2012 tentang Pedoman Pendidikan Wawasan Kebangsaan menjelaskan bahwa wawasan kebangsaan adalah cara pandang bangsa Indonesia tentang diri dan lingkungannya yang mengutamakan persatuan dan kesatuan bangsa serta kesatuan wilayah yang dilandasi Pancasila, UUD NRI 1945, Bhinneka Tunggal Ika, dan Negara Kesatuan Republik Indonesia.

Berkaitan dengan konsep tersebut, dapat dijelaskan bahwa cara pandang JFC terhadap kondisi bangsa dengan mengutamakan nilai-nilai kepedulian, kesadaran, dan semangat membangun 
adalah dasar persatuan dan kesatuan (Darmadi 2010). Sugiyarto menambahkan bahwa wawasan kebangsaan adalah cara pandang ke dalam dan ke luar bangsa dalam masalah ideologi, sosial, ekonomi, budaya, politik, dan pertahanan keamanan. Sugiyarto juga menjelaskan bahwa wawasan kebangsaan memiliki tiga dimensi, yaitu rasa kebangsaan, paham kebangsaan, dan semangat kebangsaan. Budimansyah (2010) menyimpulkan beberapa kompetensi seorang warga negara yang cerdas dan baik adalah (1) memiliki kemampuan untuk melihat dan mendekati masalah sebagai anggota masyarakat global; (2) memiliki kemampuan bekerja sama dengan orang lain dengan cara yang kooperatif dan menerima tanggung jawab atas peran/tugasnya di dalam masyarakat; (3) memiliki kemampuan memahami, menerima, menghargai, dan dapat menerima perbedaanperbedaan budaya; (4) memiliki kapasitas berpikir dengan cara yang kritis dan sistematis. Keinginan untuk menyelesaikan konflik dengan cara tanpa kekerasan; (5) memiliki keinginan untuk mengubah gaya hidup dan kebiasaan konsumtif untuk melindungi lingkungan. Kemampuan bersikap sensitif dan melindung hak asasi manusia (misalnya, hak wanita, hak etnis minoritas, dan lain-lain); (6) memiliki keinginan dan kemampuan untuk ikut serta dalam politik pada tingkat lokal, nasional, dan internasional.

\section{Proses Konstruksi Nilai-Nilai Kebangsaan melalui Fashion JFC}

Konstruksi makna fashion terkait wawasan kebangsaan dibangun melalui pengalaman dan keterlibatan peserta secara langsung agar tertanam rasa, paham, dan semangat kebangsaan. Berdasarkan hal tersebut, Undang-Undang Nomor 40 Tahun 2009 tentang Kepemudaan Pasal 17 ayat (2) memuat peran aktif pemuda sebagai kontrol sosial diwujudkan dengan: (a) memperkuat wawasan kebangsaan; (b) membangkitkan kesadaran atas tanggung jawab, hak, dan kewajiban sebagai warganegara; (c) membangkitkan sikap kritis terhadap lingkungan dan penegakan hukum; (d) meningkatkan partisipasi dalam perumusan kebijakan publik; (e) menjamin transparansi dan akuntabilitas publik; dan/atau (f) memberikan kemudahan akses informasi. Satries (2009) juga menambahkan peran pemuda sangat penting dalam pembangunan masyarakat. Keterlibatannya secara aktif dan kreatif dapat memberikan sumbangan positif untuk mengangkat derajat masyarakat sesuai dengan potensi yang dimiliki.

Pandangan ini memberikan opini bahwa pemuda sebagai generasi bangsa harus berperan aktif. Kata berperan menjelaskan adanya tindakan atau keterlibatan seseorang dalam suatu hal. Tindakan tersebut disesuaikan dengan peran yang dilakukan oleh seseorang berkaitan dengan tujuannya berdasarkan nilai atau kaidah yang berlaku di masyarakat. Kata aktif, sementara itu dapat dijelaskan sebagai proses pembentukan dari giat, mampu berinteraksi, dinamis atau berkembang secara terus-menerus. Dalam pendidikan kewarganegaraan, pembentukan warga negara yang bermutu dan bertanggung jawab dalam kehidupan masyarakat dapat dilakukan melalui partisipasi. Dalam membentuk warga negara yang memiliki partisipasi aktif dan bertanggung jawab diperlukan penguasaan sejumlah kompetensi, yaitu pengetahuan, kecakapan, dan watak (Winataputra \& Budimansyah 2012) . Sotiropoulou \& Dkk (2015) juga mengemukakan bahwa pendidikan untuk warga negara diciptakan melalui partisipasi terhadap keberadaan isu-isu yang terjadi di negara. Hubungan ini menjadikan peran sebagai warga negara adalah sangat penting karena berkaitan dengan identitas nasional. Budimansyah (Kiptiah, 2011) juga menegaskan bahwa melalui gerakan sosio-kultural kewarganegaraan ini, yaitu organisasi masyarakat yang berunsurkan sistem nilai dan norma, maka masyarakat dan komunitas dalam hal ini perlu menyediakan ruang publik bagi warga negara untuk ber-PKn. Proses pembinaan warga negara yang melibatkan organisasi kemasyarakatan yang berunsurkan nilai dan norma disebut socio cultural development. Pendidikan kewarganegaraan tidak hanya berbicara mengenai bangsa dan negara tetapi mengarah pada perilaku warga negara dengan mengonstruksikan konstribusi nasionalisme warga negara secara aktif, pemberdayaan dan pendekatan indivual secara global sebagai sebuah konsep yang ideal (Mäkinen \& Bromley 2011). 


\section{Simpulan}

Fashion dan wawasan kebangsaan memiliki keterkaitan erat dalam membangun nilai-nilai kebangsaan. Konstruksi makna dalam sebuah fashion yang ditunjukkan JFC sebagai sebuah fenomena karnaval bertujuan membangun kesadaran masyarakat akan rasa memiliki terhadap bangsa dan negaranya. Melalui fashion, JFC menyampaikan pesan sosial kepada masyarakat untuk mencintai keberadaannya dan orang lain sebagai bentuk kepedulian dalam hidup berbangsa dan bernegara. Cara pandang ini dimaknai sebagai sebuah perspektif kebangsaan yang mengutamakan kesadaran dan wawasan kebangsaan demi memperkuat persatuan dan kesatuan yang bersumber dari semangat rela berkorban dan perjuangan yang tinggi.

\section{Ucapan Terima Kasih}

Penulis mengucapkan terima kasih kepada (1) Prof. Dr. Idrus Affandi, S.H.; (2) Prof. Dr. H. Dasim Budimansyah, M.Si.; (3) Prof. Dr. Karim Suryadi, M.Si. sebagai penguji dalam sidang tesis penulis; dan (4) Prof. Dr. Sapriya, M.Ed. sebagai Ketua Departemen Pendidikan Kewarganegaraan Sekolah Pascasarjana Universitas Pendidikan Indonesia.

\section{Kepustakaan}

Aji \& Effendi, 2014. "The Roles of Culture and Tourism Service in Succeeding Semarang Night Carnival Performance in Semarang City, Central Java Province". The Internasional Journal of Social Sciences, 25(1), pp.24-25.

Arvanitidou, Z., 2011."Fashion, Gender and Social Identity". First Colloquia, pp.1-19. Available at: http://www.fashion.arts.ac.uk/media/ research/documents/zoi-arvanitidou.pdf.

Barata, D., 2010. "Fashion Sebagai Strategi Simbolik Komunikasi Non-Verbal”. Jurnal Ilmu Komunikasi, 2(1), pp.45-51.

Berek, D., 2014. "Fashion Sebagai Komunikasi Identitas Sub Budaya”. Jurnal Interaksi, 3(1), pp.56-66.
Budimansyah, D., 2010. “Tantangan Globalisasi Terhadap Pembinaan Wawasan Kebangsaan dan Cinta Tanah Air di Sekolah". Jurnal Penelitian Pendidikan, 11(1), pp.8-16.

Budimansyah \& Suryadi, 2008. PKn dan Masyarakat Multikultural, Bandung: Program Studi Pendidikan Kewarganegaraan.

Darmadi, H., 2010. Pengantar Pendidikan Kewarganegaraan. Bandung: Alfabeta.

Eicher \& Higgins, 1992. Dress and Identity. Clothing and Textiles Research Journal, 10(1), pp.1-8.

Ferreira, R., 2013. "Making a case for global education: Revisiting pre-service teacher Lesson planning methods". In M. . Plakhotnik \& S. M. Nielsen, eds. Proccedings of the 12th Annual South Florida Education Research Conference. Miami: Florida Internasional University.

Hardiman, B., 2009. Demokrasi Deliberatif, Yogyakarta: Kanisius.

Harmoko, 2009. Seri Buku Indonesia Indah: Busana Tradisional 10, Jakarta: Yayasan Harapan Kita.

Hendrariningrum \& Susilo, 2008. "Fashion dan Gaya Hidup: Identitas dan Komunikasi”. Jurnal Ilmu Komunikasi, 6(2), pp.25-32.

Henslin \& James, M., 2006. Sosiologi dengan Pendekatan Membumi, Jakarta: Erlangga.

Hidayat \& Widjanarko, 2008. Reinventing Indonesia: Menemukan Kembali Masa Depan Bangsa. Jakarta: Mizan.

Himawan, W., 2014. "Citra Budaya Melalui Kajian Historis dan Identitas: Perubahan Budaya Pariwisata Bali Melalui Karya Seni Lukis”. Journal of Urban Society's Arts, 1(1), pp.74-88.

Himawan, W. \& Nugroho, A., 2014. "Visual Tradisi dalam Karya Seni Lukis Kontemporer Sebagai Wujud Artistik Pengaruh Sosial Budaya”. Journal of Urban Society's Arts, 1(4), pp.99-109.

Huang, T.C. \& Chen, C.C., 2013. "Animating civic education: Developing a knowledge navigation system using blogging and topic map technology". Educational Technology and Society, 16(1), pp.79-92.

Jannah, R., 2012. "Jember Fashion Carnaval (JFC), Identitas Kota Jember dan Diskursus 
Masyarakat Jaringan”. Jurnal Sosiologi Masyarakat, 7(2), pp.115-133.

Jenks, C., 2013. Culture Studi Kebudayaan. Yogyakarta: Pustaka Pelajar.

Kiptiah, M., 2011.” Implementasi Integrasi Sosial Dalam Pengembanan Budaya Kewarganegaraan". Jurnal Acta Civicus: Jurnal Pendidikan Kewarganegaraan, 5(1), pp.1-20.

Kociatkiewicz \& Johansson, 2011. "City Festivals: Creatifity and Control in Stages Urban Experiences". Journal Sage: European Urban and Regional Studies, 18(4), pp.392-405.

Kuntjara, E., 2006. Penelitian Kebudayaan: Sebuah Panduan Praktis. Yogyakarta: Graha Ilmu.

Langman, L., 2003. "Culture, Identity and Hegemony: The Body in a Global Age". Current Sociology, 51(3), pp.223-247.

Mäkinen \& Bromley, 2011. "Diversity in Civic Education: Finland in Historical and Comparative Perspective CICE Hiroshima University". Journal of International Cooperation in Education, 14(2), pp.35-50.

Nuryanti, 2014. "Penanaman Wawasan Kebangsaan di Pondok Pesantren Melalui Pendidikan Sejarah". Jurnal Majalah Ilmiah Pawiyatan, 21(10), pp.124-134.

Putra \& Ahimsa, 2014. "Kebhinnekaan Budaya sebagai Modal Merespons Globalisasi”. Jurnal Literasi, 4(2), pp.167-175.

Rahmanto \& Yani, 2015. "Pemahaman Kader
PKPT IPNU-IPPNU Universitas Negeri Surabaya Tentang Wawasan Kebangsaan”. Jurnal Kajian Moral dan Kewarganegaraan, 3(3), pp.1369-1381.

Satries, 2009. "Peran Serta Pemuda dalam Pembangunan Masyarakat". Jurnal Madani, (1), pp.88-93.

Simmel, G., 2006. "Fashion". The American Journal of Sosiology, 62(6), pp.541-558.

Sotiropoulou \& Dkk, 2015. "The Civic Education in Greek Kindergartens. The Views and the Practices of Greek Kindergarten Teachers Concerning Civic Education”. International Journal of Learning, Teaching and Educational Research, 11(2), pp.55-70.

Syam, N., 2005. Islam Pesisir, Yogyakarta: LkiS.

Tauchid, M., 2015. Ki Hadjar Dewantara: Pemikiran, Konsepsi, Keteladanan, Sikap Merdeka., Yogyakarta: UST.

Wahab \& Sapriya, 2011. Teori \& Landasan Pendidikan Kewarganegaraan. Bandung: Alfabeta.

Widhagdo, 2010. Ilmu Budaya Dasar. Jakarta: Bumi Aksara.

Winataputra \& Budimansyah, 2012. Pendidikan Kewarganegaraan dalam PerspektifInternasional (Konteks, Teori, dan Profil Pembelajaran). Bandung: Widya Aksara Press.

Zen, F., 2004. NU Politik: Analisis Wacana Media. Yogyakarta: LkiS. 